\title{
O CURRÍCULO COMO CRIAÇÃO COTIDIANA: O VÍDEO COMO MATERIAL DIDÁTICO DE EDUCAÇÃO AMBIENTAL
}

\author{
Janaína Rodrigues de Freitas Machado Eduardo ${ }^{1}$ \\ Milena de Sousa Nascimento ${ }^{2}$ \\ Isabela Mazza de Lima \\ Marcelo Paraíso Alves ${ }^{4}$
}

Resumo: O presente estudo investigou a construção de conhecimentos de Educação Ambiental em uma escola pública em Volta Redonda/RJ. O seu objetivo principal foi visibilizar as ações socioambientais de professores e estudantes do $3^{\circ}$ ano do Ensino Médio e as narrativas do processo de criação de vídeos de Educação Ambiental. A pesquisa emerge dos Estudos do Cotidiano e tem como centralidade a teoria dos conhecimentos em redes. Metodologicamente, o trabalho utiliza o caderno de campo para descrever as redes de conversações constituídas no processo de pesquisa. Os dados produzidos permitiram perceber a fabricação singular de vídeos, a partir do estabelecimento da comunidade de afetos e da noção de currículo construído no cotidiano.

Palavras-chave: Educação Ambiental; Cotidiano; Redes de Conversações; Comunidade de Afetos; Criação de Vídeos.

\footnotetext{
${ }^{1}$ Centro Universitário de Volta Redonda (UniFOA); Secretaria de Estado de Educação do Rio de Janeiro, município de Volta Redonda/RJ. E-mail: janainaeduardo@yahoo.com.br

2 Centro Universitário de Volta Redonda (UniFOA); Fundação Centro de Educação a Distância do Estado do Rio de Janeiro (CECIERJ), Consórcio CEDERJ. E-mail: milenasnascimento@gmail.com

3 Secretaria de Estado de Educação do Rio de Janeiro, município de Volta Redonda/RJ. E-mail: isabelamazza@gmail.com

4 Centro Universitário de Volta Redonda (UniFOA); Instituto Federal de Educação, Ciência e Tecnologia do Rio de Janeiro, campus Volta Redonda. E-mail: marceloparaiso@outlook.com
} 


\section{Introdução}

Este artigo emerge da dissertação "Educação Ambiental e conhecimentos tecidos no cotidiano escolar" defendida no Programa de Mestrado Profissional em Ensino em Ciências da Saúde e do Meio Ambiente.

O desenvolvimento do estudo foi motivado por uma necessidade de reflexão sobre os problemas socioambientais e seus impactos no cotidiano escolar, na tentativa de compreender o modo como são constituídos os conhecimentos relacionados à Educação Ambiental (EA), visto que, a degradação ambiental aumentou significativamente nas últimas décadas (GUIMARÃES, 2011). Desse modo, ressaltamos que o desenvolvimento capitalista tem provocado o limite da carga planetária, ocasionando recordes de acidentes climáticos em diferentes países, com fenômenos cada vez mais intensos e frequentes (SANTOS, 2013a).

Nessa linha de pensamento, Santos e Chauí (2013, p. 89) mencionam que há uma estreita relação entre o modo de produção capitalista e a crise civilizatória, pois a "crise alimentar, a crise ambiental, a crise energética, a especulação financeira sobre os commodities e recursos naturais, a escassez de água potável e a privatização da água (...)" constituem a prioridade das elites do Norte global que retiram da humanidade o acesso aos direitos básicos: direito à saúde, direito à moradia, direito à natureza, direito ambiental, dentre outros.

Assim, no intuito de ampliar os conhecimentos a respeito dos problemas socioambientais e em decorrência da obrigatoriedade do desenvolvimento dessa temática em todos os níveis de ensino, conforme estabelecido pela lei 9795/99 (BRASIL, 1999), o estudo envolveu uma pesquisa sobre EA e os conhecimentos produzidos no cotidiano do Colégio Estadual Rio de Janeiro (CERJ), a partir das práticas socioculturais dos sujeitos envolvidos: professores e estudantes. Nesse sentido, coube a seguinte reflexão: Como são construídos os conhecimentos em EA no cotidiano do CERJ?

A partir desse questionamento investigamos a construção de conhecimentos de EA no CERJ. E, especificamente, buscamos visibilizar as ações socioambientais desenvolvidas pelos praticantes do cotidiano escolar, narrando a fabricação curricular de vídeos de Educação Ambiental.

Portanto, sabedores de que a escola sofre interferências sociais, políticas, econômicas e culturais da realidade em que se insere, este estudo pode adquirir relevância ao possibilitar a reflexão sobre as ações curriculares e cotidianas dos sujeitos envolvidos no processo, favorecendo a produção de um material didático e a discussão da temática socioambiental. 


\section{Percurso teórico-metodológico}

O Colégio Estadual Rio de Janeiro (CERJ) localiza-se no bairro Sessenta, em Volta Redonda/RJ, município do Vale do Paraíba Fluminense (CEPERJ, 2017). No estudo, realizado em 2017, os sujeitos da pesquisa totalizaram 92 estudantes do $3^{\text {o }}$ ano do Ensino Médio e professores de diferentes disciplinas.

Por se tratar de um recorte da pesquisa, neste trabalho serão apresentados os dados referentes à participação de uma professora de Geografia e da professora pesquisadora, que leciona o componente curricular de Biologia. No intuito de manter o sigilo dos participantes do estudo, as narrativas foram identificadas com as iniciais dos nomes abreviadas.

Os estudantes pesquisados, majoritariamente são oriundos de famílias da classe média baixa e residem na proximidade do colégio. Alguns já estão no mercado de trabalho, sobretudo, no setor de serviços. E, outros cursam o Ensino Técnico concomitante em instituições públicas ou privadas.

A pesquisa está centrada nos Estudos com o Cotidiano (OLIVEIRA; SGARBI, 2008) e na noção de conhecimentos em redes (OLIVEIRA, 2012a), pela necessidade de visibilizar práticas cotidianas invisibilizadas pela racionalidade moderna, que compreende a realidade por meio de metodologias universalizantes desconsiderando a singularidade das criações cotidianas dos estudantes.

Sendo assim, neste trabalho o currículo é entendido como uma criação cotidiana (OLIVEIRA, 2012a), visto que surge das ações ordinárias (CERTEAU, 2014) dos sujeitos da escola e representa o currículo possível, construído a partir da proposta oficial estabelecida da Secretaria de Estado de Educação do Rio de Janeiro (SEEDUC-RJ), mas singularmente ressignificado pelos sujeitos que configuram o espaço do CERJ.

Outro aspecto relevante deste estudo emergiu da concepção de narrativas enredadas às experiências dos praticantes, pois "o narrador retira da experiência o que ele conta" (BENJAMIN, 1994, p. 201).

Cabe ressaltar que para Benjamin (1994) a experiência é concebida em oposição ao conceito de vivência. Para o autor a vivência advém do ato de estar presente a um evento, ser a testemunha ocular. Vincula-se à fugacidade da ocorrência e sua duração. E, associa-se apenas ao indivíduo, sua história pessoal e a sua cotidianidade, fato relacionado ao modo de vida moderno.

Em contraposição, o autor considera a experiência que se acumula, se desdobra e se prolonga na relação do sujeito com a comunidade em que está inserido permitindo a sedimentação desse conhecimento, a partir dos critérios concedidos por essa coletividade.

Assim, a experiência aqui é entendida no entrelaçamento entre Benjamin (1994) e Bondía (2002), visto que a experiência é tudo aquilo que nos passa cotidianamente, "o que nos acontece, o que nos toca. A cada dia se passam muitas coisas, porém, ao mesmo tempo, quase nada nos acontece"

revista brasileira educação ambiental 
(BONDÍA, 2002, p. 21).

O caderno de campo e a rede de conversações foram os instrumentos usados na produção dos dados da pesquisa. O caderno de campo possibilitou o registro das narrativas (textos, imagens, vídeos, conversas) dos sujeitos, por meio da anotação detalhada de informações, observações, debates e reflexões que surgiram no decorrer da pesquisa. E, a rede de conversações foi concebida como a arte de conversar, como possibilidade para 0 reconhecimento da narrativa do outro (CARVALHO, 2009; CERTEAU, 2014).

Seguindo o rastro certeauniano, Carvalho (2017) reitera o caráter múltiplo das redes de conversações, visto que, diversos discursos e formas de narrar o mundo estão enredados (textos, imagens, sons, vídeos, encontros, experiências e histórias de vida). Assim, o acesso aos conhecimentos de EA, singularmente tecidos às redes de conversações foi feito via entrevistas aos professores e produções textuais e audiovisuais dos estudantes.

Por fim, ressaltamos que a discussão dos dados produzidos na pesquisa foi realizada, a partir das noções de artefactualidade discursiva, autoria e prazer de Santos (2013b), artesania de Certeau (2014) e redes de conhecimentos de Oliveira (2012a). Cabe ainda frisar que o estudo foi aprovado pelo Comitê de Ética na Pesquisa, com o CAAE, no 66189717.1.0000.523.

\section{Articulação da racionalidade estético-expressiva e o princípio da comunidade}

Para Santos (2013b), o projeto de modernidade está assentado sobre dois pilares. O pilar da regulação, constituído pelos princípios do Estado, Comunidade e Mercado e o pilar da emancipação, formado por três racionalidades: a racionalidade estético-expressiva da arte e da literatura, a racionalidade moral-prática da ética e do direito e a racionalidade cognitivainstrumental da ciência.

Para o autor existe uma correspondência entre os princípios e as racionalidades. Desse modo, a racionalidade estético-expressiva articula-se ao princípio da comunidade; a racionalidade moral-prática vincula-se ao princípio do Estado e a racionalidade cognitivo-instrumental tem uma correspondência direta com o princípio do mercado.

Todavia, considerando os impactos ambientais e sua relação com o pensamento moderno, podemos perceber a desarticulação dos pilares da regulação e da emancipação (SANTOS, 2011). Assim, o mercado prevaleceu no pilar da regulação e a racionalidade cognitivo-instrumental da ciência e da tecnologia sobressaiu às demais racionalidades do pilar da emancipação privilegiando a hipercientificização e a hipermercadorização. Situação que potencializou os problemas socioambientais: devastação, miséria, concentração de renda, entre outros.

Pensando no enfrentamento do desequilíbrio provocado pela ênfase do Revbea, São Paulo, V. 13, № 4: 09-29, 2018. 
mercado e da racionalidade cognitivo instrumental, o autor reitera que a racionalidade estético-expressiva da arte e da literatura (artefactualidade discursiva, autoria, prazer) e o princípio da comunidade (solidariedade e participação) são as aberturas que a modernidade deixou para se instaurar um processo de intervenção social em virtude de ambos terem resistido ao processo de "diferenciação técnico-científica através da qual a racionalidade cognitivo-instrumental colonizou os princípios do Estado e do Mercado" (SANTOS, 2011, p. 75).

Em relação à artefactualidade discursiva, o autor salienta que "todas as obras de arte têm de ser criadas ou construídas” (SANTOS, 2011, p. 77). Elas resultam de uma intenção e de um ato específico e se estabelecem por meio de um discurso argumentativo direcionado a um público-alvo.

Ao discutir essa noção, Oliveira (2012b, p. 7) considera que a artefactualidade discursiva possui como uma de suas características a "dimensão artística da produção dos discursos, ou seja, o fato de eles serem permeados pelos sentidos (aisthesis) e não apenas pela cognição". Assim, pensar a partir dessa ótica permitiria romper com a ideia de que o único conhecimento possível seria via conhecimento científico e em decorrência da racionalidade indolente.

Em relação à autoria, Santos (2011) revela que essa noção abarca os conceitos de iniciativa, autonomia, criatividade, autenticidade e originalidade. $E$, foi o elemento que mais resistiu à colonização. Oliveira (2012b, p. 7) ressalta que a noção de autoria permite devolver "aos sujeitos a responsabilidade sobre suas vidas e destinos, a autoria do mundo social que, se é quem os tece, é também tecido por eles".

Assim, ao discutir a noção de prazer, a autora menciona que o caráter lúdico recupera a legitimidade do critério de "prazerosidade" perdido com a modernidade, visto que, a razão indolente suprimiu o prazer "de nossos fazeres cotidianos" (OLIVEIRA, 2012b, p. 7).

Se a partir do pilar da emancipação as noções supracitadas permitem recuperar os processos emancipatórios, para Şantos (2011) no pilar da regulação o caminho seria viabilizado pelo princípio da comunidade, por meio da solidariedade e da participação.

Acerca disso, Tristão (2005) afirma que a solidariedade confere uma dimensão ética ao conhecimento emancipação, enquanto a participação confere uma dimensão política a esse pilar. Com isso, a autora ressalta que, "como seres humanos, dependemos da solidariedade que, por sua vez, pressupõe a participação" (TRISTÃO, 2005, p. 257).

Devemos entender que as ideias de solidariedade e de participação instauradas no princípio da comunidade são, para Santos (2011), associadas respectivamente, à dimensão ética e política da vida social. Por outro lado, esse entendimento nos inspira a compreender a noção de cidadania e de democracia de maneira diferente da estabelecida pela vertente liberal. 
Para Tristão (2005, p. 258) romper com o pensamento liberal requer compreender que até os anos de 1980 a ênfase na participação predominava a referência do aspecto quantitativo, dados que a participação emergia da quantidade de pessoas imbuídas de diferentes objetivos coletivos como: reivindicação de direitos e benefícios sociais, exercício do direito de voto, estabelecimento de greves na conquista de salários e melhorias de trabalho, dentre outras.

Portanto, para Tristão (2005) essa concepção de participação reduz a noção de cidadania aos direitos sociais, visto que desconsidera a subjetividade. Segundo a autora, a partir da década de 1980 a participação resgata a importância da individualidade e da afetividade, deixando-se perder "valores como igualdade e liberdade, valores éticos, como autonomia, emancipação, respeito à diferença e à diversidade, que se configuram como pano de fundo desse cenário" (TRISTÃO, 2005, p. 259).

Nessa ótica, a autora reforça a necessidade de se potencializar 0 acionamento de políticas de formação autoconsciente na tessitura das comunidades, pois são os encontros, o diálogo, o compartilhamento e as conexões estabelecidas nas relações em redes que forjam as comunidades interpretativas de Santos (2011) e as comunidades heterológicas de Carvalho (2009).

Partindo das ideias supramencionadas, consideramos que a razão moderna age na perspectiva do pensamento abissal, pois estabelece 0 conhecimento científico como única e exclusiva fonte de verdade, excluindo tudo o que está fora de sua compreensão, porque estabelece que para além de sua fronteira há somente inexistência, invisibilidade e outros saberes como cultura, filosofia e religião (SANTOS, 2007).

Sendo assim, o pensamento pós-abissal (SANTOS, 2010) pode enfrentar a monocultura imposta pela racionalidade moderna, a partir do exercício da ecologia dos saberes. A ecologia de saberes "se baseia na ideia de que o conhecimento é interconhecimento", portanto, tem por premissa a inesgotável diversidade de saberes do mundo (SANTOS 2007, p. 85).

De acordo com Santos (2007), a racionalidade moderna deve ser confrontada com outros saberes e critérios, a partir do diálogo entre o saber científico e o popular. Sendo assim, é relevante explicar que a ecologia dos saberes não pretende "descredibilizar" as ciências nem pregar a "anticiência". O que se pretende é que a ciência não seja monocultural e possa integrar uma ecologia mais ampla de saberes (SANTOS, 2007).

Entretanto, devido à diferença epistemológica existente entre os diversos saberes, Santos (2008) propõe a tradução e, explicita que "cada saber conhece melhor os seus limites e possibilidades comparando-se com outros saberes" (p. 29). Assim, a diferença epistemológica existente exige que a comparação aconteça por meio de procedimentos de busca de proporção e correspondência pela tradução. Segundo o autor para que isso ocorra é necessário que esses procedimentos:

Revbea, São Paulo, V. 13, № 4: 09-29, 2018. 
Sejam levados a cabo por todos os saberes que compõem um dado círculo de ecologia de saberes. Na acepção que aqui lhe dou, a tradução é tradução recíproca. Através dela, a diferença epistemológica, ao ser assumida por todos os saberes em presença, torna-se uma diferença tendencialmente igual. Os procedimentos de proporção e correspondência são procedimentos indiretos que permitem aproximações sempre precárias ao desconhecido a partir do conhecido, ao estranho a partir do familiar, ao alheio a partir do próprio (SANTOS, 2008, p. 29).

Entre esses procedimentos, Santos (2008, p. 29) menciona "sinais, símbolos, conjecturas, enigmas, pistas, perguntas, paradoxos, ambiguidades, etc.". E, destaca que sua utilização, ainda que não elimine a incompletude de cada saber, os aproxima. Enquanto, o aumento da incompletude é astúcia da douta ignorância, a douta ignorância por sua vez, possibilita a aquisição máxima de consciência acerca da incompletude.

Dessa forma, ao exercitar a tradução vislumbramos que os procedimentos aplicados "para conhecer outros saberes são os mesmos com que cada saber conhece a experiência do mundo em geral e não apenas a experiência epistemológica do mundo" (SANTOS, 2008, p. 30).

Para Oliveira (2012a), reconhecer a diversidade epistemológica do mundo e a existência da pluralidade de formas de conhecimento exige a renúncia à epistemologia geral e a adoção da ecologia de saberes "como uma contra epistemologia que busca ir além da mera crítica" (p. 32).

Além disso, como a pluralidade de saberes é infinita, para confrontar o conjunto de saberes criados no exercício de uma ecologia de saberes, Santos (2008) propõe a artesania das práticas, que considera diferentes perspectivas, usos do conhecimento e experiências (CERTEAU, 2014).

Nesse sentido, Esteves (2014) ressalta que vivemos em diversos espaços na sociedade como o espaço doméstico, o da comunidade, o da cidadania, o do mercado, o da produção e o mundial, propostos por Boaventura de Sousa Santos. Portanto, todos os lugares onde o saber é convocado a converter-se em experiência transformadora são campos de enunciação da ecologia de saberes.

Por tudo que foi exposto, as aulas ocorreram no formato de rodas de conversas (REIS; FLORES, 2017), nas quais as narrativas registradas revelaram a influência do pensamento moderno na fragmentação do conhecimento, na ênfase da memorização dos conteúdos e na predominância da percepção conservadora de meio ambiente. E, apontaram a preocupação dos estudantes em relação à poluição atmosférica gerada pela Companhia Siderúrgica Nacional (CSN) e o despejo de esgoto e lixo no ribeirão Brandão.

Essas evidências suscitaram a discussão do conceito de Educação Ambiental e da relevância dos aspectos social, político e histórico na reflexão 
das causas da degradação ambiental. Assim, foi discutida a diferença entre EA Tradicional ou Conservadora e a EA Crítica ou Socioambiental e estimulada a investigação dos impactos ambientais no entorno do CERJ, movimentos que resultaram na fabricação de vídeos de EA.

\section{Criação cotidiana e curricular de vídeos de Educação Ambiental}

Ao considerar o exposto por Oliveira (2012b, p. 7), este estudo ressalta a importância do trabalho pedagógico como elemento fundado no prazer, posto que a relevância da recuperação dessa dimensão se relaciona com 0 "envolvimento prazeroso dos professores com o seu cotidiano". Nesse sentido, a produção efetuada a partir das redes de conversações propiciou a fabricação coletiva dos vídeos sobre impactos ambientais.

A atividade que será descrita a seguir foi desenvolvida com os estudantes da turma 3001. E, possibilitou observar a motivação gerada nos estudantes pela oportunidade de ir a campo, produzir dados e entrevistar a comunidade. Segundo Oliveira (2012a, p. 47) "a noção de autoria assegura a dimensão ativa do sujeito na produção de conhecimentos e práticas sociais", sendo assim:

O autor é originador, é sujeito, sem que, para isso, tenha que definir seus temas e obras como objetos controláveis e manipuláveis - nem os alunos, nem os conteúdos, nem as práticas pedagógicas. Por meio dessa recuperação do sujeitoautor, bem como pelo nexo estabelecido entre aquele que produz sua intencionalidade e sua obra - presente na noção de artefactualidade (OLIVEIRA, 2012a, p. 47).

Outro fato que interferiu na proposição do vídeo foi a possiblidade de associar os conteúdos vistos nas aulas à realidade local, por meio do registro de impactos ambientais no entorno escolar, conforme percebemos na narrativa a seguir:

Estudante B.R.: "Como o vídeo apresenta imagens e áudio ele pode ampliar o entendimento e favorecer a aprendizagem".

É importante considerar na narrativa do estudante a ampliação das linguagens sobre o mundo e, simultaneamente, enfatizar que a elaboração da referida produção (vídeo) se aproxima da ecologia dos saberes. Para Santos (2007) a ecologia dos saberes opõe-se à lógica de produção da não existência (Pensamento Abissal), a monocultura do saber. E, "visa criar uma nova forma de relacionamento entre o conhecimento científico e outras formas de conhecimento" (SANTOS, 2007, p. 108).

Outro aspecto significativo do estudo foi a opção dos estudantes pela 
selecionados conforme as sugestões dos estudantes e a orientação do Currículo Mínimo de Biologia da Secretaria de Estado de Educação do Rio de Janeiro (SEEDUC-RJ, 2012).

Cabe frisar que, apesar de partirmos do que foi estabelecido pela orientação curricular da rede estadual, a produção dos estudantes se aproximou da noção de currículo praticado (OLIVEIRA, 2013), pois, "professores e alunos se expressam e criam sentidos próprios para acontecimentos, conhecimentos, convicções presentes nos diferentes cotidianos escolares" (OLIVEIRA, 2013, p. 87). O quadro 1 apresenta os temas selecionados e a distribuição dos alunos em grupos.

Quadro 1: Organização dos estudantes em grupos para a produção de vídeos.

\begin{tabular}{cl}
\hline GRUPOS & \multicolumn{1}{c}{ IMPACTOS AMBIENTAIS } \\
\hline 01 & Efeito Estufa e agravamento do aquecimento global \\
\hline 02 & Poluição no ribeirão Brandão \\
\hline 03 & Queimadas e perda de biodiversidade \\
\hline 04 & Desmatamento, erosão e assoreamento \\
\hline 05 & Ciclos Biogeoquímicos (N, C, O) \\
\hline 06 & Buraco na camada de Ozônio \\
\hline 07 & Chuva ácida \\
\hline
\end{tabular}

Fonte: Autoria própria.

Para Oliveira (2013, p. 387) pensar os currículos a partir da noção de currículo que se constrói no cotidiano, nos permite ressignificar os conteúdos, visto que são produções articuladas aos conhecimentos múltiplos, valores e crenças, sentimentos e formas expressivas dos sujeitos que participam do processo de aprendizagem. Portanto, em diferentes espaços, os docentes "criam currículos, modificando normas e textos de políticas educacionais [...], usando aquilo que sabem/sentem/desejam em diálogo com aquilo que Ihes é supostamente imposto".

Por reconhecer a potência da racionalidade estético-expressiva e as noções de autoria e "prazerosidade", apresentamos algumas narrativas que evidenciaram a autonomia do autor e a recuperação do prazer no processo de criação dos vídeos:

Estudante G.: A criação de vídeo facilitou a aprendizagem, pois foi uma atividade diferente das outras. Ela facilita 0 entendimento, porém dá muito mais trabalho.

Estudante A. As atividades ajudaram na aprendizagem e eu gostei muito, pois o vídeo deu uma variada nas tarefas.

Estudante E.: Os vídeos foram uma maneira divertida de aprender. Eu pude aprender mais sobre os temas ao assistir os vídeos dos outros colegas e também ao associar as pesquisas e o conhecimento adquirido nas aulas. 
Estudante I.: Gosto de atividades novas e gostei da ideia de fazer o vídeo. Essa atividade possibilita que a gente aprenda de perto a matéria das aulas.

Estudante M. D.: $O$ bom é que o trabalho exige pesquisa e com isso acabamos aprendendo mais. Trabalhos como esse devem ser passados mais vezes, porque têm vários benefícios como atividade em equipe, desenvolvimento de pesquisa, etc.

Estudante J.V.: Com as informações que buscamos aprendemos a importância que tem o lugar que habitamos, pois achamos que a poluição não nos afeta e nos enganamos, pois as vezes não afeta diretamente, mas gera consequências.

Estudante J.C.: Essa atividade me ajudou a pensar sobre o que eu posso fazer para melhorar meu bairro, a cidade e 0 planeta, mesmo que seja uma pequena transformação. (Grifos nossos).

Essas narrativas evidenciaram que criação de vídeos favoreceu a aprendizagem, sobretudo, por requerer a pesquisa e estimular a reflexão sobre os impactos ambientais, bem como o trabalho coletivo. Assim, se por um lado, a atividade de produção de vídeos de Educação Ambiental possibilitou a recuperação da autoria ao incentivar a busca de informações e o exercício de uma produção singularizada, caracterizada pelo modo ordinário (CERTEAU, 2014) como os estudantes ressignificaram os conteúdos apreendidos pelo grupo no transcorrer do bimestre. Por outro, possibilitou a recuperação do prazer, pois os estudantes ressaltaram que gostaram de realizá-la, principalmente por ser atividade diversificada, diferente das tarefas que costumam desenvolver.

Nesse sentido, destacamos o prazer como modo de oposição ao enclausuramento provocado pela razão indolente e a monocultura do saber, visto que a racionalidade estético-expressiva foi a menos colonizada pela razão moderna. Assim, "fora do alcance da colonização, manteve-se a irredutível individualidade intersubjetiva do homo ludens" (SANTOS, 2011, p. 76).

Esse aspecto merece ser ressaltado por considerarmos as proposições de Huizinga (1999), que defende a tese de que o lúdico corresponde a uma das noções mais primitivas da realidade humana, precedendo inclusive a própria cultura, permanecendo subjacente a todas as formas de expressões humanas: artes, competição, pensamento, dentre outros, não sendo, portanto, passível de um controle totalitário.

Entre os estudantes do grupo responsável pelo tema Poluição no ribeirão Brandão surgiu uma dúvida sobre a forma de apresentação da atividade. Eles estavam preocupados e questionaram as regras de avaliação. Nesse sentido, importa é que "professor e alunos se assumam epistemologicamente curiosos" (FREIRE, 2011, p. 83). Assim: 
A dialogicidade não nega a validade de momentos explicativos, narrativos, em que o professor expõe ou fala do objeto. $O$ fundamental é que professor e alunos saibam que a postura deles [...] é dialógica, aberta, curiosa, indagadora e não apassivada, enquanto fala e enquanto ouve.

Dessa maneira, pensando em critérios, os estudantes foram orientados a produzirem vídeos com até oito minutos, evitando locais com ruídos para preservar o áudio. O material produzido deveria ser entregue em DVD no prazo de três semanas.

Os critérios que deveriam ser considerados na elaboração dos vídeos, tais como a criatividade, qualidade do material, coerência com a temática, apresentação de conceitos, contextualização, diálogo com a realidade local e necessidade de participação efetiva dos integrantes do grupo, também foram discutidos nesse momento. Além disso, conversamos sobre a importância de pesquisar o impacto ambiental e como ele nos afeta. Dessa forma, discutimos a necessidade de buscarmos dados sobre o percentual de tratamento de esgoto na cidade, lançamento de esgotos e densidade populacional dos bairros cortados por esse corpo hídrico e, sobretudo, a relevância do envolvimento da comunidade, no intuito de informá-la a respeito do seu papel de cidadão frente ao direito socioambiental.

O modo como os estudantes construíram os conhecimentos sobre a poluição no ribeirão Brandão nos chamou a atenção, uma vez que todos produzem esgoto e seu despejo in natura provoca a eutrofização dos mananciais. Guimarães (2011, p. 27) afirma que para obter transformações significativas necessitamos "superar as perspectivas individualizantes, nos realizando no coletivo e pelo coletivo". A narrativa da estudante "J.C." nos permite perceber indícios do movimento realizado pelos estudantes na construção dos seus conhecimentos sobre EA:

Estudante J.C.: Pretendemos conversar com moradores, professores da escola e ir à Associação de Moradores. Hoje em dia $40 \%$ do esgoto é tratado na cidade, mas, as pessoas jogam lixo na beira do ribeirão.

Sendo assim, os estudantes buscaram dados sobre o percentual de tratamento de esgoto na cidade e de lançamento de esgoto nos bairros cortados pelo ribeirão. Outro aspecto relevante a ser ressaltado, foi como o grupo envolveu a comunidade no intuito de obter dados sobre os problemas específicos que impactam a comunidade. $O$ que nos remeteu aos seguintes questionamentos: Até que ponto esse movimento dos estudantes emergiu como um indício de ação coletiva? Seria esse um primeiro movimento? Primeiro buscar informação, para posteriormente, em coletividade cobrar o poder público sobre questões ligadas aos impactos ambientais gerados em

Revbea, São Paulo, V. 13, № 4: 09-29, 2018.

revista brasileira educação ambiental 
todas as esferas da sociedade?

Nesse contexto, Guimarães (2011, p. 26) orienta que não devemos nos render ao pessimismo e incentiva a adoção da perspectiva crítica ou socioambiental, a partir do debate profundo das causas da crise, intrinsicamente ligado ao modo de produção capitalista. Segundo o autor, o caráter crítico reside em "perceber, problematizando e complexificando, os antagonismos e complementaridades da realidade em suas múltiplas determinações [...]".

Diante do interesse dos estudantes foi proposta a atividade de elaboração de roteiros dos vídeos. Inicialmente, os roteiros foram desenvolvidos individualmente. Eles continham ideias, informações sobre o impacto ambiental e recursos necessários para a produção dos vídeos. Posteriormente, as ideias foram discutidas em sala e os estudantes elegeram as que mais atendiam aos interesses da equipe.

Assim, a rede de conversações (CARVALHO, 2009) favoreceu a produção de roteiros coletivos, caracterizados pela singularidade e peculiaridade do currículo cotidianamente criado (OLIVEIRA, 2012a), conforme percebemos nas narrativas a seguir:

Estudante A.C.C.: Vamos entrevistar o povo na rua e perguntar os prejuízos econômicos e ao ar causado pelas queimadas. A queimada na maioria das vezes é provocada por ação humana e uma minoria tem causa natural. Vamos gravar no celular e montar um telejornal.

Estudante M.: Definimos os recursos que serão usados e dividimos as tarefas. Serão pesquisados ciclos biogeoquímicos e sua relação com os problemas ambientais.

\begin{abstract}
Estudante B.: Faremos entrevistas na escola e buscaremos imagens dos impactos ambientais da CSN e outras empresas. Queremos fazer como um documentário para associar os gases liberados na cidade e o agravamento do Efeito estufa. (Grifos Nossos).
\end{abstract}

Deve ser ressaltada a opção de alguns estudantes pelo formato de bancada de telejornal, conforme mencionado pela discente "A.C.C.". Quadros e Quadros Júnior (2013) em seu estudo sobre vídeos educativos no YouTube apontaram essa característica e revelaram que "as narrativas audiovisuais ora seguem modelos existentes, como um telejornal, ora se apropriam de partes de outros vídeos para produzir um novo produto" (QUADROS; QUADROS JÚNIOR, 2013, p. 3).

Retornando ao entrelaçamento dos fios da pesquisa, explicitaremos o 
referido problema, conforme mencionado pela discente "J.C.". Acerca disso, Freire (2011, p. 31-32) orienta:

Por que não aproveitar a experiência que têm os alunos de viver em áreas da cidade descuidadas pelo poder público para discutir, por exemplo, a poluição dos riachos e dos córregos e os baixos índices de bem-estar das populações, os lixões e os riscos que oferecem à saúde das gentes [...] Por que não estabelecer uma "intimidade" entre os saberes curriculares fundamentais aos alunos e a experiência social que eles têm como indivíduos?

Dessa forma, percebemos que ao buscar a comunidade os estudantes tiveram a oportunidade de contextualizar os conhecimentos obtidos em sala de aula, rompendo com uma lógica de ensino tradicional e promovendo uma aprendizagem significativa, capaz de proporcionar mudanças no modo como percebem a realidade em que estão inseridos. Os estudantes se esforçaram para associar o impacto ambiental pesquisado à realidade local. Eles foram a campo, conversaram com moradores, estudantes, professores, funcionários e comerciantes. As narrativas a seguir evidenciam os conhecimentos produzidos em rede (OLIVEIRA, 2012a) e viabilizados pelas redes de conversações (CARVALHO, 2009):

Estudante Ma.: Ao abordar a poluição no ribeirão Brandão pesquisamos a erosão e o desmatamento. Além de conversar com o pessoal da Associação de Moradores e entrevistar professores e funcionários do colégio, também procuramos na internet.

Estudante G.C.: Procuramos relacionar as atividades realizadas em sala com pesquisas em diversos sites onde buscamos conceitos e curiosidades. Esse método de trabalho foi interessante, pois é um jeito descontraído de aprender, querendo ou não, é preciso se aprofundar no assunto para criar algo com qualidade.

Estudante l.: Conseguir manter contato durante a execução do vídeo e entrar em acordo com a equipe em relação às ideias foram os maiores desafios.

Estudante J.G.: Para realizar essa atividade minha equipe teve que aprender sobre assoreamento que sinceramente, a gente desconhecia. Foi preciso aprofundar conhecimentos para formular questões da entrevista e superar a timidez. (Grifos nossos). 
Outro aspecto que nos chamou a atenção na pesquisa, emergiu na parte técnica da construção dos vídeos e o modo como os estudantes foram superando as dificuldades encontradas:

Estudante T.: Tivemos dificuldades na edição, porque não sabíamos editar, nem conhecíamos o formato do vídeo que íamos fazer.

Estudante P.H.: Eu não sabia editar, mas pedi ajuda ao meu primo. Parece que é fácil, mas é dificílimo e demora muito tempo, principalmente, para por legenda e acertar a velocidade certa entre fala e texto.

Estudante C.: Eu particularmente, não sabia o que era assoreamento. Então ao produzir o vídeo pude compreender esse assunto. É um trabalho que traz conhecimentos, mas é bem difícil devido à edição. Acho que seria mais fácil se fosse entregue em pen drive. (Grifos nossos).

Ao pensar nos praticantes do colégio e suas tessituras, recordamos o modo certeauniano, visto que criaram seus próprios percursos no intuito de superar as dificuldades encontradas: artes de fazer (CERTEAU, 2014). Para o autor, o homem ordinário, o sujeito comum, inventa maneiras de burlar a conformação e a ordem dominante, alterando normas, códigos, objetos, de maneira a atender os seus anseios e necessidades.

Para fabricar os vídeos os estudantes reinventaram a maneira de burlar as dificuldades: as oscilações na velocidade da internet na escola, a falta de um técnico no Laboratório de Informática, a disponibilidade de apenas dez computadores e esses com um sistema operacional livre - diferente do usado em suas casas.

Desse modo, a referida fabricação foi possível pelo uso de táticas e os diferentes modos de fazer (CERTEAU, 2014) e em decorrência da solidariedade estabelecida nas redes de relações. Assim, no decorrer da construção dos vídeos, houve a troca de informações, a indicação de softwares, o auxílio na edição de vídeo, o empréstimo de equipamentos (notebook, tablets, smartphones, pen drive) e a cessão de internet entre os estudantes de diferentes grupos. Também merece destaque, a participação da comunidade escolar, conforme mencionado anteriormente pelos estudantes.

Os estudantes pensaram, elaboraram, finalizaram e apresentaram suas produções, movimento que incentivou a participação e o protagonismo dos estudantes, ampliando a discussão sobre os impactos ambientais. Como eles apresentaram dificuldade para entregar as produções em DVD, pois não sabiam gravar arquivos de vídeos nessa mídia, a entrega foi feita em pen drive. Além disso, foi discutida e posteriormente, realizada uma atividade de apresentação dos vídeos. Os estudantes gostaram da proposta devido à oportunidade de mostrar suas produções, visualizar as criações aos demais adolescentes e revisar os conteúdos do primeiro bimestre.

Revbea, São Paulo, V. 13, № 4: 09-29, 2018. 


\section{Ampliando a rede: novas experiências e mais gente na roda}

No decorrer da produção dos vídeos, após ser entrevistada pelos estudantes do grupo "Chuva ácida", a professora "F.", que leciona Geografia demonstrou interesse em constituir a rede de conversações e articular os conteúdos do Currículo Mínimo de Geografia e de Biologia relacionados aos impactos ambientais.

Diante do movimento estabelecido, a professora interessou-se em conhecer os estudos do cotidiano e a noção de construção de conhecimentos em redes (OLIVEIRA, 2012a) solicitando a indicação de teóricos no intuito de compreender os aspectos político, epistemológico e metodológico desse campo. Trazer à tona a referida aproximação se deve a sua relevância, sobretudo, se considerarmos que na perspectiva explicitada não há espaço para hierarquia, nem para reduzir o outro a sua funcionalidade. Acerca disso, Freire (2011, p. 111) argumenta que:

O sonho que nos anima é democrático e solidário, não é falando aos outros, de cima para baixo, sobretudo, como se fôssemos os portadores da verdade a ser transmitida aos demais, que aprendemos a escutar, mas é escutando que aprendemos a falar com eles. Somente quem escuta paciente e criticamente o outro, fala com ele [...] O que jamais faz quem aprende a escutar para pode falar impositivamente. (Grifos do autor).

Dessa forma, tivemos o cuidado de não "usar" a professora e os conteúdos de Geografia para "atender às necessidades" da pesquisa. Principalmente, porque a "reconstrução horizontalizante de relações entre saberes, culturas e usos do conhecimento" é primordial à trajetória epistemológica e política que traçamos (OLIVEIRA, 2012a, p. 42).

Por isso, resolvemos que no $2^{-}$bimestre daríamos continuidade à fabricação de vídeos. Mas, dessa vez os vídeos relacionariam conteúdos de Geografia, a partir de uma abordagem interdisciplinar e transversal da temática ambiental. Aproveitando o desenrolar da conversa, foram estabelecidos os critérios de avaliação e a forma de orientação dos estudantes a respeito da elaboração de roteiros individuais, discussão de ideias, construção de roteiro coletivo e produção de vídeos. Assim, foi definido que os estudantes deveriam se organizar em sete grupos em cada turma. As duas turmas de $3^{\circ}$ ano do Ensino Médio do colégio (3001 e 3002) participaram dessa parte do estudo.

Os temas foram indicados pelas professoras com a participação dos estudantes. Devido à solicitação dos estudantes, os sete temas foram sorteados (Quadro 2). Finalizada a conversa sobre a apresentação dos conteúdos e os critérios de avaliação, orientamos a elaboração do roteiro individual, no qual os estudantes deveriam realizar uma pesquisa para aprofundar teoricamente a temática da sua equipe.

revista brasileira educação ambiental 
Quadro 2: Temas abordados na produção de vídeos que entrelaçaram Geografia e Educação Ambiental.

\begin{tabular}{cl}
\hline GRUPOS & \multicolumn{1}{c}{ Temas } \\
\hline 01 & Marketing e consumo \\
\hline 02 & Mobilidade Urbana \\
\hline 03 & Industrialização \\
\hline 04 & Matéria prima \\
\hline 05 & Poluição Sonora \\
\hline 06 & Biotecnologia e Bioética \\
\hline 07 & Mercado de Trabalho. \\
\hline
\end{tabular}

Fonte: Autoria própria

No decorrer das aulas, os estudantes traçaram ideias para a produção dos vídeos. Essas ideias surgiram por meio da busca de conceitos, informações e dados estatísticos e a partir da tentativa de contextualizar a questão socioambiental à realidade do entorno do colégio e na cidade de Volta Redonda. Dessa forma, quando os estudantes entregaram o roteiro individual foram incentivados a discutir as ideias propostas e a elaboração de um roteiro em grupo. Assim, os roteiros coletivos foram tecidos a partir da troca, do diálogo, da reunião e da eleição das melhores ideias.

Convém mencionar a maciça participação dos estudantes e a qualidade dos vídeos produzidos. Os vídeos criados sobre "Mobilidade urbana", "Industrialização", "Biotecnologia", e "Poluição sonora" mereceram destaque por relacionarem os temas propostos ao estudo dos impactos ambientais, contextualizar os dados pesquisados à situação ambiental do CERJ e de Volta Redonda e, por fim, por envolver a comunidade escolar, suas famílias e moradores do entorno.

Os estudantes responsáveis pela criação do vídeo sobre Mobilidade Urbana fotografaram e filmaram o trânsito na cidade de Volta Redonda, entrevistaram motoristas que atuam no transporte coletivo e divulgaram algumas mudanças discutidas na $1^{\text {a }}$ conferência municipal realizada sobre a temática. Enquanto os discentes que produziram o vídeo sobre Industrialização se dedicaram a contar o processo de construção da Companha Siderúrgica Nacional, primeira indústria desse porte na América Latina, cuja história esta intrinsicamente atrelada ao surgimento de Volta Redonda e também ao processo de urbanização e industrialização brasileiro (LOPES, 2004).

Além disso, a equipe que produziu o vídeo sobre Biotecnologia buscou informações com um biólogo que atua em uma rede de farmácias de manipulação e foi à feira livre, que é montada próximo ao colégio, para ouvir a opinião dos moradores a respeito do uso de agrotóxicos na produção de alimentos e do consumo de alimentos transgênicos pela população. Enquanto, a equipe responsável pela produção do vídeo sobre Poluição Sonora, após pesquisar o assunto sentiu a necessidade de entrevistar um médico, uma Revbea, São Paulo, V. 13, № 4: 09-29, 2018. 
veterinária, uma técnica em Segurança no Trabalho e uma advogada para ampliar o entendimento sobre a como a poluição nos afeta e a legislação pertinente.

Esses movimentos favoreceram a discussão da temática ambiental no CERJ. Dessa forma, os praticantes estabeleceram redes (OLIVEIRA, 2012a) e participaram da criação curricular coletiva, como podemos perceber em suas falas:

Estudante R.: Buscamos as leis e entrevistamos um médico para entender como os ruídos prejudicam a nossa saúde [...]. Foi muito difícil gravar no zoológico, mas, a gente queria abordar como a poluição sonora afeta os animais.

Estudante Ma.: Pesquisamos alimentos transgênicos na feira livre que é montada perto escola. Conversamos com moradores e muitos não sabiam o que é biotecnologia, nem suas aplicações.

Estudante A.C.F.: Gravamos imagens na feira livre, montada todas as quartas-feiras aqui pertinho da escola, onde pesquisamos sobre agrotóxicos e transgênicos. $E$, conseguir convencer os moradores a participar nem sempre é fácil.

Estudante L.: Nosso crescimento foi fantástico. A gente não sabia editar nada. Mas, se virou para aprender a criar vídeos, pesquisar sobre o meio ambiente e relacionar os temas estudados aos impactos ambientais que afetam nossa escola e a cidade. (Grifos nossos).

Assim, ao buscar o entendimento acerca das narrativas foi percebido que a criação de vídeos de Educação Ambiental possibilitou a construção de conhecimentos em redes, já que para produzi-los, os estudantes buscaram os conceitos, pesquisaram dados no município de Volta Redonda, ouviram e envolveram a comunidade escolar e, além disso, aprenderam a filmar e editar. Portanto, as redes de conversações nas quais os sujeitos estão imersos se estabeleceram como o que é tecido junto, possibilitando o surgimento da comunidade de afetos, uma vez que nesse nível de complexidade e entrelaçamento a afetividade assume uma função especial. Para Carvalho (2009, p. 209) "são, portanto, os afetos que dão consistência aos vínculos e/ou instituem laços sociais pela confiança recíproca estabelecida".

Nessa ótica, as abordagens de comunidade, a solidariedade e a cooperação "aparecem como elementos da constituição do 'comum' como algo que acontece na e em relação" (CARVALHO, 2009, p. 163). Esses elementos ficaram evidentes na troca de ideias na elaboração de roteiros, na partilha de experiências e saberes relacionados à filmagem, edição e gravação dos vídeos e no uso compartilhado de equipamentos no decorrer das atividades, e em decorrência na escuta da comunidade escolar, por meio da participação nas entrevistas, como foi percebido na narrativa do estudante "Ma.". 
De acordo com Tristão (2005) é nos encontros, no diálogo e na partilha que se forjam as comunidades interpretativas. Por isso, a solidariedade e a participação foram elementos fundamentais para o êxito nas criações e a ruptura das práticas impostas pela racionalidade moderna, pois na fabricação dos vídeos os estudantes buscaram outros modos de fazer e usar a Educação Ambiental, na medida em que driblaram as dificuldades encontradas, como a insuficiência de computadores, a falta de softwares e outros equipamentos no colégio, além da pouca experiência na produção audiovisual, conforme mencionado pelo estudante "L.".

Convêm destacar que para produzirem os vídeos, os praticantes realizaram uma criação curricular coletiva, a partir do estabelecimento da solidariedade e da participação, elementos que, para Santos (2013b) compõe o princípio da comunidade, portanto, menos colonizado pelo projeto de modernidade. Dessa forma, concebemos a referida produção como um indício (GINZBURG, 1989) de superação da lógica metonímica, visto que permitiu desinvibilizar ações cotidianas dos estudantes do CERJ.

Oliveira (2012a, p. 68) revela que os conhecimentos "se tecem em redes constituídas de todas as experiências individuais e coletivas que vivemos". Nessa perspectiva os conhecimentos tecidos pelos sujeitos são criados e transformados permanentemente, sendo, portanto, provisórios. Nesse contexto, devemos ressaltar que as criações dos estudantes favoreceram a constituição de comunidades interpretativas, conforme denominada por Santos (2011) ou comunidades heterológicas para Carvalho (2009). Comunidades se baseiam no diálogo, na leitura e na tradução para alcançar a construção do comum no espaço e no tempo.

Acerca disso, Tristão (2012, p. 217) explica que a tradução cultural deve ser entendida como uma metáfora transgressora da tradução linguística ao "traduzir movimentos de práticas e culturas sustentáveis entre comunidades e escolas, entre um e outro". Nessa ótica, o currículo deve ser entendido "como redes de conversações e ações complexas [...] para a recriação de saberes, fazeres e afetos da/na escola" (CARVALHO, 2009, p. 188).

Por tudo que foi exposto e com base nas ideias de Oliveira (2012a), a criação curricular realizada no cotidiano do CERJ pode ser entendida como uma contribuição emancipatória, ao possibilitar a discussão das questões ambientais e a produção coletiva de vídeos, enquanto experiência social, centrada na horizontalidade de relações e possibilitada pelas redes de conhecimentos constituídas pelos estudantes e professores inscritos.

\section{Considerações finais}

Considerando que a investigação objetivou visibilizar as ações socioambientais desenvolvidas pelos praticantes de uma escola pública localizada no município de Volta Redonda/RJ, descrevemos o modo como a produção de vídeos foi utilizada pedagogicamente para construir conhecimentos sobre Educação Ambiental.

Revbea, São Paulo, V. 13, № 4: 09-29, 2018. 
Os dados produzidos evidenciaram a construção do currículo no cotidiano do colégio, pois apesar de partirmos da matriz estabelecida oficialmente pela SEEDUC-RJ, a pesquisa revelou a possibilidade da contextualização dos conteúdos viabilizados pelas impressões, crenças e modos de vida de estudantes e professores da escola investigada. Outro aspecto relevante obtido com 0 estudo foi a construção coletiva de conhecimentos de EA.

Esses dados revelaram que as redes de conversações permitiram a constituição da comunidade de afetos, visto que, a solidariedade, a participação e o compartilhamento promoveram as trocas de experiências. E, possibilitaram que os estudantes superassem dificuldades técnicas, tecnológicas e também conceituais, relacionadas aos conteúdos específicos de EA (impactos ambientais e temas ligados à Geografia).

Para finalizar, ressaltamos que a aproximação da racionalidade estético-expressiva da arte e da literatura (autoria, artefactualidade discursiva e prazer) permitiu a mobilização dos estudantes e, simultaneamente, a motivação e 0 interesse dos discentes para 0 desenvolvimento do processo de aprendizagem, favorecendo a contextualização e a ressignificação dos conteúdos propostos.

\section{Referências}

BENJAMIN, W. Magia e técnica, arte e política: Obras escolhidas. 7. ed. São Paulo: Editora Brasiliense, 1994.

BONDÍA, L. J. Notas sobre a experiência e o saber da experiência. Revista Brasileira de Educação, 2002, n. 19, p.20-28.

BRASIL. Política Nacional de Educação Ambiental, Lei no 9.795 de 27 de abril de 1999. Disponível em: <http://www.planalto.gov.br/ccivil 03/leis/L9795.htm > Acesso em 05 jun. 2017.

CARVALHO, J.M. O cotidiano escolar como comunidade de afetos. Petrópolis: Editora DP\&A; Brasília, DF: CNPq, 2009.

CARVALHO, J.M. A formação de professores como redes de conversações: por um devir-docência. In: OLIVEIRA, I.B.; REIS, G. Pesquisas com formação de professores e rodas de conversa e narrativas de experiências. Petrópolis, RJ: DP\&A, 2017, p. 63-82.

CENTRO ESTADUAL DE ESTATÍSTICAS PESQUISAS E FORMAÇÃO DE SERVIDORES PÚBLICOS DO RIO DE JANEIRO - CEPERJ. Centro de Estatísticas, Estudos e Pesquisas. Divisão regional, mesorregiões, microrregiões geográficas e municípios. Disponível em: $<$ http://www.ceperj.ri.gov.br/ceep/info territorios/divis regional.html>. Acesso em 08 Dez. 2017.

CERTEAU, M. A Invenção do cotidiano. v. 1. Artes de fazer. Tradução Ephaim Ferreira Alves. 13. ed. Petrópolis: Vozes, 2014. 
ESTEVES, S.M. Práticas emancipatórias e democracia: em busca de saberesfazeres libertários nos currículos praticados. Dissertação (Mestrado em Educação). Rio de Janeiro: UERJ, 2014. 106 f.

FREIRE, P. Pedagogia da autonomia: saberes à prática educativa. São Paulo: Paz e Terra, 2011.

GINZBURG, C. Mitos, emblemas e sinais: morfologia e história. São Paulo: Companhia das Letras, 1989.

GUIMARÃES, M. Armadilha paradigmática na educação ambiental. In: LOUREIRO, C.F.B.; LAYRARGUES, P.P.; CASTRO, R.S. (Orgs.). Pensamento Complexo, dialética e educação ambiental. São Paulo: Cortez, 2011, p. 15-29.

HUIZINGA, J. Homo Ludens. Perspectiva: São Paulo, 1999.

LOPES, J.S.L. Conflitos Ambientais no Brasil. In: ACSELRAD, H. (Org). A Ambientalização dos Conflitos em Volta Redonda. Rio de Janeiro: RelumeDumará, 2004. p. 217-244.

OLIVEIRA, I.B.; SGARBI, P. Estudos do cotidiano \& Educação. Belo Horizonte: Autêntica, 2008.

OLIVEIRA, I.B. O currículo como construção cotidiana. Petrópolis, RJ: DP\&A, Rio de Janeiro: FAPERJ, 2012a. 136 p.

OLIVEIRA, I.B. Contribuições de Boaventura de Sousa Santos para a reflexão curricular: princípios emancipatórios e currículos pensadospraticados. Revista e-Curriculum, v. 8, n. 2, 2012b. Disponível em: <http://revistas.pucsp.br/index. $\mathrm{php/} \mathrm{curriculum/article/view/10984>.} \mathrm{Acesso} \mathrm{em} 10$ out. 2017.

OLIVEIRA, I.B. Currículo e processos de aprendizagem-ensino: políticaspráticas educacionais cotidianas. Currículo sem Fronteiras, São Paulo, v. 13, n. 3, p. 375-391, 2013. Disponível em: <http://www.curriculosem fronteiras.org/vol13iss3articles/oliveira.pdf >. Acesso em 05 fev. 2018.

QUADROS, C.I.; QUADROS JÚNIOR, I.B. Aspectos comunicacionais da educação nas mídias sociais digitais: o caso do Youtube. Programa de Pós Graduação em Comunicação, Universidade Federal do Paraná. Curitiba, 2013.

REIS, G.; FLORES, R.L.B. Sobre a hegemonia e conhecimento: uma proposta de diálogo em busca de desinvisibilizações de práticas curriculares cotidianas. In: OLIVEIRA, I.B.; REIS, G. Pesquisas com formação de professores e rodas de conversa e narrativas de experiências. Petrópolis, RJ: DP\&A, 2017, p. 17-44.

SANTOS, B.S. Renovar a teoria crítica e reinventar a emancipação social. tradução Mouzar Benedito. São Paulo: Boitempo, 2007.

SANTOS, B.S. A filosofia à venda, a douta ignorância e a aposta de Pascal. Revista Crítica de Ciências Sociais. 80, 2008, p.11-43. Disponível em: $<$ https://www.ces.uc.pt/bss/documentos/A filosofia a venda RCCS80 Marco2 008.pdf>. Acesso em 11 nov. 2017.

Revbea, São Paulo, V. 13, № 4: 09-29, 2018. 
SANTOS, B.S. Para além de do pensamento abissal: das linhas globais a uma ecologia de saberes. In: SANTOS, Boaventura de Sousa; MENEZES, Maria Paula. (Orgs.) Epistemologias do Sul. São Paulo: Cortez, 2010, p.31-83.

SANTOS, B.S. A crítica da razão indolente: contra o desperdício da experiência. 8. ed. São Paulo: Cortez, 2011.

SANTOS, B.S. Direitos humanos, democracia e desenvolvimento. São Paulo. Cortez, 2013a.

SANTOS, B. S. Pela mão de Alice: o social e o político na pós-modernidade. 14. ed. São Paulo: Cortez, 2013b.

SANTOS, B.S.; CHAUÍ, M. Direitos Humanos, democracia e desenvolvimento. São Paulo: Cortez, 2013.

SECRETARIA DE ESTADO DE EDUCAÇÃO DO RIO DE JANEIRO. SEEDUCRJ. Biologia - $3^{\circ}$ ano do Ensino Médio. In: Currículo Mínimo de Ciências e Biologia. Rio de Janeiro, 2012. p. 13.

TRISTÃO, M. Tecendo os fios da educação ambiental: o subjetivo e o coletivo, o pensado e o vivido. Educação e Pesquisa, v. 31, n. 2, 2005. Disponível em:< http://www.scielo.br/pdf/ep/v31n2/a08v31n2.pdf>. Acesso em 15 set. 2017.

TRISTÃO, M. A educação ambiental e a emergência de uma cultura sustentável no cenário da globalização. Revista INTERthesis, Florianópolis, v.9, n.1, Jan./Jul., 2012. p. 207-222. Disponível em:< https://periodicos.ufsc.br/index.php/interthesis/article/view/1807-

1384.2012v9n1p207/22511>. Acesso em 10 set. 2017. 